\title{
Produtividade da soja em sucessão a cultivos de outono-inverno
}

\author{
Soybean yield affected by previous cropping in fall-winter
Luan Marlon Ribeiro', Gessí Ceccon ${ }^{2}$, Ivan Arcanjo Mechi', Anna Luiza Farias dos Santos ${ }^{1}$, Ricardo Fachinelli $^{1}$, Priscila Akemi Makino ${ }^{1}$ \\ ${ }^{1}$ Universidade Federal da Grande Dourados (UFGD), Faculdade de Ciências Agrárias (FCA), Rod. \\ Dourados - Itahum, km 12, CEP 79805-095, Cidade Universitária, Dourados, MS. \\ E-mail: luanmarlon@hotmail.com \\ ${ }^{2}$ Embrapa Agropecuária Oeste (CPAO), Dourados, MS.
}

Recebido em: 13/07/2017

Aceito em:14/08/2017

\begin{abstract}
Resumo: A sucessão soja-milho safrinha predomina na produção de grãos na região Centro-oeste, e a produtividade das culturas pode estar relacionada com os níveis de cobertura do solo. Objetivou-se avaliar a produtividade das cultivares de soja BRS 284 e BRS 360 RR em sucessão a cultivos de outono-inverno. O trabalho foi realizado na área experimental da Embrapa Agropecuária Oeste, em Dourados, MS, nas safras 2014/15 e 2015/16. O delineamento experimental foi em blocos casualizados com parcelas subsubdivididas em quatro repetições. As parcelas principais foram os anos, as subparcelas os cultivos de outono-inverno (Brachiaria ruziziensis, consórcio de milho com B. ruziziensis, milho solteiro e feijão-caupi), e as subsubparcelas as cultivares de soja (BRS 284 e BRS 360 RR). Na floração avaliou-se altura de plantas, massa seca de folhas e de hastes. Na colheita avaliou-se o número de grãos por planta, massa de 100 grãos e produtividade de grãos, em todos os cultivos de outono-inverno. Os dados foram submetidos à análise de variância e as médias comparadas pelo teste de Tukey a 5\% de probabilidade. Em 2015/16 a soja apresentou maior massa de 100 grãos, altura de plantas e rendimento de grãos em relação à safra 2014/15, quando houve restrição hídrica. A cultivar BRS 360 RR apresentou maior número de grãos por planta e consequentemente maior produtividade $\left(3.218 \mathrm{~kg} \mathrm{ha}^{-1}\right)$ em relação a cultivar BRS 284. A maior produtividade de grãos em 2014/15 (1.882 e $1.880 \mathrm{~kg} \mathrm{ha}^{-1}$ ) foi em sucessão ao milho safrinha e B. ruziziensis, enquanto que 2015/16 não houve diferença. Em anos com deficiência hídrica, o benefício das culturas de outono-inverno sobre a produtividade da soja é mais relevante.
\end{abstract}

Palavras-chaves: Brachiaria spp., Glycine max, plantio direto, rotação de culturas, Zea mays

Abstract: The soybean-maize succession predominates in grain production in the Midwest, and crop productivity may be related to soil cover levels. The objective of this study was to evaluate a productivity of BRS 284 and BRS 360 RR soybean cultivars in succession to autumn-winter crops. The work carried out in the experimental area of Embrapa Agropecuária Oeste, in Dourados, MS, in the 2014/15 and 2015/16 harvests. The experimental design was in a randomized block with sub - divided plots in four replications. As subplots the autumn-winter crops (Brachiaria ruziziensis, corn intercropping with B. ruziziensis, single corn and cowpea), and as subsubparcels as soybean cultivars (BRS 284 and BRS 360 RR). During flowering, plant height, dry mass of leaves and stems were evaluated. At harvest, the number of grains per plant, mass of 100 grains and grain yield were evaluated in all autumn-winter crops. The data were submitted to analysis of variance and as averages compared by the Tukey test at 5\% of probability. In 2015/16, soybean showed the highest mass of 100 grains, plant height and grain yield in relation to the 2014/15 crop, when there was water restriction. A BRS $360 \mathrm{RR}$ cultivar presented higher number of grains per plant and consequently higher productivity $\left(3,218 \mathrm{~kg} \mathrm{ha}^{-1}\right)$ compared to the cultivar BRS 284 . Greater grain yield in 2014/15 (1,882 and 1,880 $\mathrm{kg} \mathrm{ha}^{-1}$ ) Succession to safrinha corn and B. ruziziensis, whereas in 2015/16 there was no difference. In years with water deficiency, the benefit of autumn-winter crops on soybean yield is more relevant.

Keywords: Brachiaria spp., Glycine max, tillage, crop rotation, Zea mays

Ribeiro et al., v.11, n.40, p. 120-131, Dourados, 2018 


\section{(-) \\ Revista Agrarian \\ ISSN: 1984-2538}

\section{Introdução}

A baixa produtividade da soja na região Centro Oeste pode estar relacionada com os baixos níveis de cobertura do solo, principalmente no estado do Mato Grosso do Sul. Ribeiro et al. (2015) verificaram que a cobertura do solo é um dos fatores ligados ao aumento de produtividade, e as maiores produtividades estão em lavouras com maiores coberturas do solo.

A sucessão soja-milho safrinha, pode provocar a degradação do solo, e proporcionar condições favoráveis para maior incidência de doenças, insetos-pragas e plantas daninhas, sendo necessário introduzir outras espécies para rotação de cultura (Tecnologias, 2013).

Considerando que a soja é uma cultura de grande importância para o agronegócio brasileiro, preconiza-se o seu cultivo em plantio direto e em sistemas de integração lavoura-pecuária, pois a mesma apresenta boa adaptação a esta tecnologia (Ricce et al., 2011; Kluthcouski et al., 2000).

A alternância de culturas, viabiliza o sistema plantio direto e potencializa seus efeitos benéficos sobre a produção agropecuária (Tecnologias, 2013), visando a manutenção da umidade, melhoria na estrutura física e química do solo, maior acúmulo de matéria orgânica no solo e maior produtividade das culturas cultivadas nesse sistema (Chioderoli et al., 2010).

Nas regiões tropicais um grande desafio para a manutenção do plantio direto são as altas taxas de decomposição do material vegetal, o que demanda por grandes quantidades de palha (Chioderoli et al., 2012), devendo-se considerar a utilização de gramíneas e leguminosas, anuais ou semiperenes para essa finalidade (Assis et al., 2003; Carneiro et al., 2008).

Desta forma algumas culturas podem englobar o sistema, diversificando o tipo de cobertura; como opção temos o feijão-caupi (Vigna unguiculata (L.) Walp.), que pode possibilitar melhorias na fertilidade do mesmo, podendo ser usado como adubo verde (Freire Filho et al., 2005), outro opção seria a Brachiaria ruziziensis em cultivo solteiro ou consorciado com milho, podendo proporcionar maior estabilidade produtiva das culturas em sucessão, pela ciclagem de nutrientes e conservação do solo (Costa et al., 2012) e quanto mais tardia for realizada a dessecação da forrageira, maior será a quantidade de palha sobre o solo, favorecendo melhores condições para cultivo da soja em sucessão (Ceccon et al., 2009).

O sistema de integração-lavoura-pecuária, pode reduzir os custos de produção no melhor controle de plantas daninhas, e produção de altas quantidades de palha, isso associado à pecuária, pode-se produzir até três safras por ano, com a produção de grãos e carne (Balbino et al., 2012).

Com isso o uso de espécies de coberturas capazes de acumular massa na superfície e romper camadas compactadas pelo sistema radicular tem papel importante (Salton, 1999). A diversificação de plantas com sistemas radiculares capazes de explorar diferentes profundidades do solo, com potencial diferenciado de ciclagem, proporciona melhor equilíbrio dos nutrientes e na atividade biológica do solo, favorecendo o estabelecimento da cultura em sucessão (Reis et al., 2007).

O trabalho foi realizado com o objetivo de avaliar a produtividade da soja em sucessão aos cultivos de outono-inverno em duas épocas de semeadura em plantio direto.

\section{Material e Métodos}

O trabalho foi realizado na área experimental da Embrapa Agropecuária Oeste, no município de Dourados, Mato Grosso do Sul, nas coordenadas $22^{\circ} 13^{\prime} \mathrm{S}$ e $54^{\circ} 48^{\prime} \mathrm{W}$ a $408 \mathrm{~m}$ de altitude, em área sob plantio direto há 15 anos. O solo é classificado como Latossolo Vermelho distroférrico de textura muito argilosa (Santos et al., 2013). A análise do solo na camada $0-0,20 \mathrm{~m}$ apresentou os seguintes resultados: $\mathrm{pH}\left(\mathrm{CaCl}_{2} 0,01\right.$ $\left.\mathrm{ml}^{-1}\right)=6,2 ; \mathrm{V}=79,3 \% ; \mathrm{MO}\left(\mathrm{g} \mathrm{kg}^{-1}\right)=37,9 ; \mathrm{P}(\mathrm{mg}$ $\left.\mathrm{dm}^{-3}\right)=57,3 ; \mathrm{K}\left(\mathrm{cmol}_{\mathrm{c}} \mathrm{dm}^{-3}\right)=1,0 ; \mathrm{Ca}\left(\mathrm{cmol}_{\mathrm{c}} \mathrm{dm}^{-}\right.$ $\left.{ }^{3}\right)=6,5 ; \mathrm{Mg}\left(\mathrm{cmol}_{\mathrm{c}} \mathrm{dm}^{-3}\right)=2,8 \mathrm{e} \mathrm{Al}\left(\mathrm{cmol}_{\mathrm{c}} \mathrm{dm}^{-3}\right)=$ 2,7 .

O clima de Dourados, segundo a classificação de Köppen, é do tipo Am (Tropical Monçônico), com verões quentes e invernos secos, temperaturas máximas observadas nos meses de dezembro e janeiro e temperaturas mínimas entre maio e agosto, coincidindo com chuvas excedentes na primavera - verão e déficit hídrico no outono inverno (Fietz et al., 2013).

Os dados de precipitação e temperaturas durante a condução do experimento nos anos agrícolas 2014/15 e 2015/16, foram obtidos na Estação Meteorológica da Embrapa Agropecuária Oeste localizada a $300 \mathrm{~m}$ da área experimental. O total da precipitação no período experimental em 


\section{(0) \\ Revista Agrarian \\ ISSN: 1984-2538}

2014/15 foi de $517 \mathrm{~mm}$, e no ano seguinte 2015/16

foi de $1.317 \mathrm{~mm}$ (Figura 1).

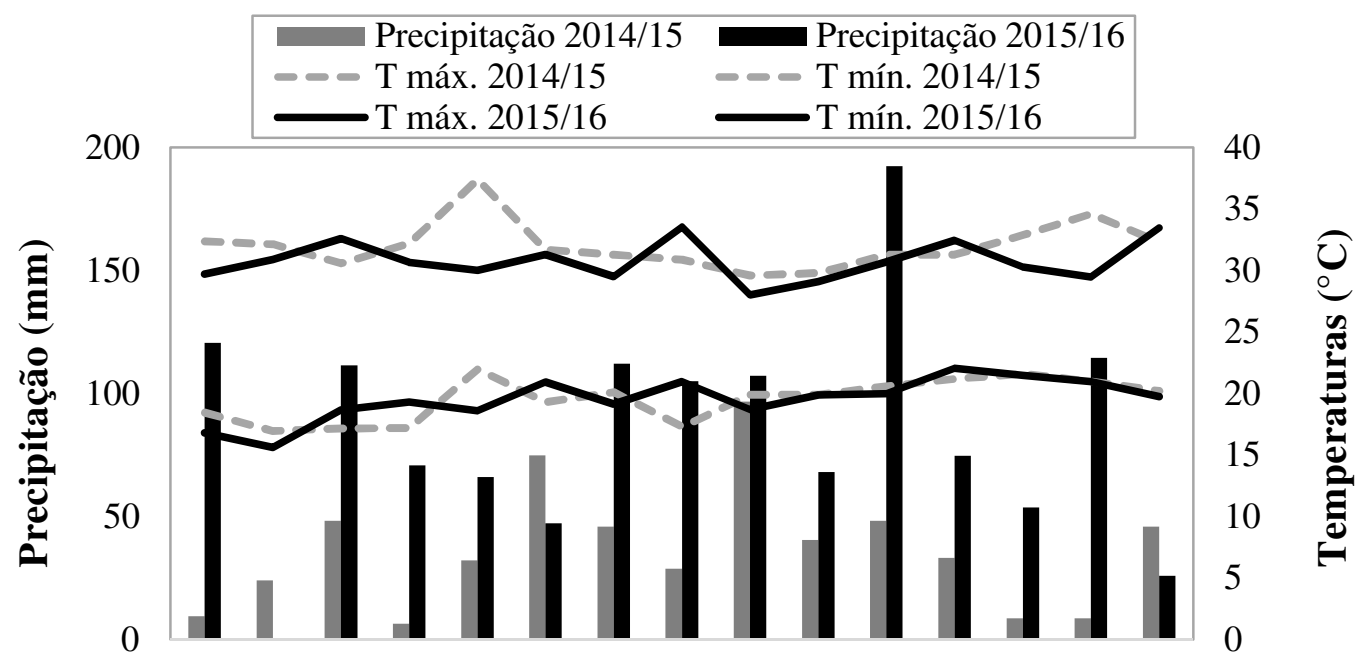

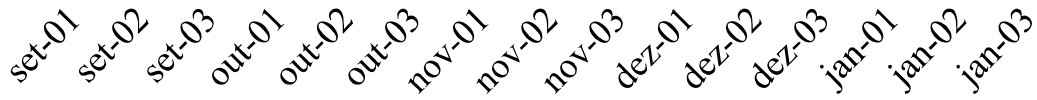

Figura 1. Valores descendais de precipitação, temperaturas máximas e mínimas registradas, durante o cultivo da soja-verão 2014/15 e 2015/16, em Dourados, MS. Fonte: Embrapa (2016).

A área experimental é manejada em Plantio Direto há 15 anos, num esquema de sucessão de culturas há sete anos, onde no outono-inverno é cultivado feijão-caupi (var. guariba), milho safrinha, Brachiaria ruziziensis e consórcio de milho com $B$. ruziziensis, com a soja no verão. $\mathrm{O}$ experimento foi realizado nos anos agrícolas 2014/15 e 2015/16, com as cultivares de soja BRS 284 e BRS 360 RR no verão, em sucessão a cultivos de outono-inverno.

$\mathrm{O}$ delineamento experimental foi $\mathrm{em}$ blocos casualizados com parcelas subsubdivididas em quatro repetições. As parcelas principais foram os anos agrícolas (2014/15 e 2015/16), as subparcelas os quatros cultivos de outono-inverno constituídos pelo feijão-caupi (var. guariba), $B$. ruziziensis, milho safrinha e consórcio de milho com B. ruziziensis e as subsubparcelas foram constituídas pelas duas cultivares de soja BRS 284 e BRS 360 RR, com unidades experimentais de sete linhas de seis metros de comprimento com $0,45 \mathrm{~m}$ de espaçamento entre linhas.

A cultivar BRS 284 é convencional, ciclo precoce, crescimento indeterminado, possui grupo de maturação 6.3, moderadamente resistente ao nematoide de galha Meloidogyne javanica. A BRS 360 RR, é transgênica (tolerância ao herbicida glifosato. RR2 PRO TM), ciclo precoce, crescimento indeterminado, possui grupo de maturação 6.2 (Embrapa, 2013).

$\mathrm{Na} B$. ruziziensis houve pastejo por animais a partir de abril e no consórcio milho com B. ruziziensis após a colheita do milho, em julho.

Foram coletados somente na safra 2014/15 amostras de milho safrinha, braquiária e plantas daninhas presentes na superfície do solo, em quatro amostras de um metro quadrado, a fim de caracterizar os resíduos vegetais dos tratamentos. Os resíduos foram separados em plantas daninhas e resíduos dos cultivos, secados em estufa a $60^{\circ} \mathrm{C}$ até peso constante e depois convertendo os dados em kg ha-1 . No feijão-caupi praticamente não havia resíduos vegetais, visto que após a colheita do feijão-caupi foi realizada a dessecação das parcelas para eliminação das plantas daninhas.

A quantidade total de resíduos na $B$. ruziziensis foi de $2.052 \mathrm{~kg} \mathrm{ha}^{-1}$, no milho safrinha foi de $6.697 \mathrm{~kg} \mathrm{ha}^{-1}$ (4.745 de milho $+1.952 \mathrm{de}$ plantas daninhas), no consórcio milho com $B$. ruziziensis foi de $5.383 \mathrm{~kg} \mathrm{ha}^{-1}$, (2.921 de milho + 2.462 de braquiária)

A dessecação da área foi realizada aos 15 dias antes da semeadura da soja, utilizando herbicida gliphosate na dose $1,08 \mathrm{~kg}$ e. a. ha ${ }^{-1}$, para supressão de plantas daninhas e braquiária dos cultivos de outono-inverno. 


\section{(-) \\ Revista Agrarian \\ ISSN: 1984-2538}

A semeadura foi realizada em $09 / 10 / 2014$, e 08/10/2015, utilizando semeadora modelo PAR 2800 regulada para distribuição de $300 \mathrm{~kg} \mathrm{ha}^{-1} \mathrm{da}$ fórmula NPK 00-20-20, na profundidade de $10 \mathrm{~cm}$, com população de 244.444 plantas ha ${ }^{-1}$.

As sementes de soja foram tratadas com fipronil e tiofanato-metílico, ambos na dose de $1 \mathrm{~g}$ i. a. por $\mathrm{kg}$ semente $\mathrm{e}$ inoculadas com Bradyrhizobium japonicum (100 ml para $50 \mathrm{~kg}$ de sementes), e semeadas a $5 \mathrm{~cm}$ de profundidade.

Para o controle de insetos-pragas foi realizado uma aplicação de flubendiamida $(120 \mathrm{ml}$ i. a. ha ${ }^{-1}$ ) e para o controle de doenças foi realizada uma aplicação de trifloxistrobina e protioconazol (400 ml i. a. ha ${ }^{-1}$ ) em 11/11/2014 e 08/11/2015 respectivamente.

As avaliações morfológicas das plantas de soja foram realizadas quando a cultura apresentava pleno florescimento (estágio R2) em 18/11/2014 e 16/12/2015.

Foram coletadas manualmente 5 plantas de cada parcela para a determinação de altura de plantas (AP), área foliar por planta (AFP), massa seca de folhas, de haste e massa seca total (folhas + haste).

A área foliar foi medida no aparelho marca LI-COR®, modelo LI 3100, determinando a área foliar em $\mathrm{cm}^{2}$. O índice de área foliar (IAF) foi calculado pela relação entre a área foliar da planta e a área de solo ocupada.
A massa da matéria seca foi obtida pela secagem em estufa com ar forçado à $60^{\circ} \mathrm{C}$ por até 72 horas, e as produtividades de massa seca de folha (PMSF), produtividade de massa seca de haste (PMSH) e produtividade de massa seca total (PMST), foram estimados por $\mathrm{kg} \mathrm{ha}^{-1}$ com base na população final de plantas de soja.

A maturação fisiológica da soja ocorreu em 26/01/2015 e 01/02/2016, quando realizou-se a coleta das plantas em 2 linhas de $3 \mathrm{~m}$ de comprimento, espaçadas por $0,45 \mathrm{~m}$, utilizando-se colheitadeira de parcela (wintersteiger), para a determinação dos componentes de produtividade, para o cálculo, com correção da umidade para $13 \%$.

Os dados foram submetidos a análise de variância e as médias comparadas pelo teste de Tukey, a 5\% de probabilidade, utilizando-se o programa estatístico Sisvar (Ferreira, 2000).

\section{Resultados e Discussão}

A análise de variância indicou efeito isolado de anos para altura de plantas, índice de área foliar, produção de massa seca de folha, produção de massa seca de haste e produção de massa seca total. Houve efeito isolado de cultivos para altura de plantas. Verificou-se interação somente de anos x cultivos para altura de plantas (Tabela 1).

Tabela 1. Resumo da análise de variância de altura de plantas (AP), índice de área foliar (IAF), produção de massa seca de folhas (PMSF), produção de massa seca de haste (PMSH) e produção de massa seca total (PMST) em anos, cultivos e cultivares de soja, em Dourados-MS.

\begin{tabular}{|c|c|c|c|c|c|c|}
\hline \multirow[b]{2}{*}{ Fator de variação } & \multirow[b]{2}{*}{ GL } & \multicolumn{5}{|c|}{....................................Quadrado médio } \\
\hline & & AP & IAF & PMSF & PMSH & PMST \\
\hline Bloco & 3 & 2,206 & 1,877 & 130650,753 & 475749,063 & 1102656,258 \\
\hline Anos & 1 & $58594,253^{*}$ & $159,106^{*}$ & $23501613,263^{*}$ & $108111879,353^{*}$ & $232426261,208^{*}$ \\
\hline Erro (a) & 3 & 14,144 & 0,929 & 76643,584 & 266555,300 & 619117,430 \\
\hline Cultivos & 3 & $89,768^{*}$ & $0,451^{\mathrm{ns}}$ & $78392,973^{\mathrm{ns}}$ & $508829,466^{\mathrm{ns}}$ & $957922,947^{\mathrm{ns}}$ \\
\hline Anos x Cultivos & 3 & $110,381^{*}$ & $1,442^{\mathrm{ns}}$ & $208821,669^{\text {ns }}$ & $547526,301^{\mathrm{ns}}$ & $1247968,097^{\mathrm{ns}}$ \\
\hline Erro (b) & 18 & 16,958 & 0,843 & 86736,752 & 255654,158 & 622527,603 \\
\hline Cultivares & 1 & $83,037^{\mathrm{ns}}$ & $0,000^{\mathrm{ns}}$ & $1779,679^{\text {ns }}$ & $322452,202^{\mathrm{ns}}$ & $372133,550^{\mathrm{ns}}$ \\
\hline Anos x Cultivares & 1 & $26,137^{\mathrm{ns}}$ & $2,019^{\mathrm{ns}}$ & $20827,901^{\mathrm{ns}}$ & $175164,221^{\mathrm{ns}}$ & $75187,011^{\mathrm{ns}}$ \\
\hline Cultivos x Cultivares & 3 & $58,995^{\mathrm{ns}}$ & $0,678^{\mathrm{ns}}$ & $81837,844^{\mathrm{ns}}$ & $422974,633^{\mathrm{ns}}$ & $873542,282^{\mathrm{ns}}$ \\
\hline $\begin{array}{c}\text { Anos x Cultivos x } \\
\text { Cultivares }\end{array}$ & 3 & $88,911^{\mathrm{ns}}$ & $1,347^{\mathrm{ns}}$ & $118061,682^{\mathrm{ns}}$ & $458780,833^{\mathrm{ns}}$ & $1031275,808^{\mathrm{ns}}$ \\
\hline Erro (c) & 24 & 14,435 & 1,012 & 129130,785 & 361208,372 & 865416,722 \\
\hline
\end{tabular}




\section{(0)}

\section{Revista Agrarian}

ISSN: 1984-2538

\begin{tabular}{ccccccc} 
Total & 63 & 60450,688 & 218,791 & 29195895,050 & 127901100,433 & 277184473,839 \\
Média & & 63,30 & 3,59 & $1.153,85$ & $1.777,50$ & $2.931,36$ \\
\hline C.V.\% & & 6,00 & 28,00 & 31,14 & 33,81 & 31,74 \\
\hline
\end{tabular}

$\mathrm{GL}=$ graus de liberdade, *significativo e ${ }^{\text {ns }}$ não significativo $(\mathrm{p}>0,05)$.

A soja em 2014/15, apresentou menor AP em relação a cultura em 2015/16. Bárbaro et al. (2006), acreditam que a AP está mais ligada com a densidade populacional do que os recursos ambientais disponíveis. No entanto, AP da soja neste experimento pode estar mais relacionados com índices de pluviosidade do que densidades populacionais, corroborando com Argenta et al. (2001).

Durante o primeiro decêndio de setembro ao terceiro decêndio de janeiro os índices de pluviosidade foram maiores em 2015/16, apresentando um acúmulo de $1.317 \mathrm{~mm}$ durante todo o ciclo da cultura, ao contrário em 2014/15 quando a soja passou por estresse hídrico durante todo o ciclo, apresentando um acúmulo menor de água de $517 \mathrm{~mm}$. Para Gava et al. (2015), quando a cultura recebe um estresse em alguma fase importante de seu desenvolvimento, ela pode apresentar redução de AP, diminuição de biomassa e até abortamento de flores e vagens.
A soja possui exigências hídricas que aumentam progressivamente do início da emergência à formação das vagens, mantendo-se altas até a maturação fisiológica (Mundstock \& Thomas, 2005), exigindo entre 450 a $850 \mathrm{~mm}$ de capacidade real de água disponível, para a produção considerável de biomassa e grãos (Carvalho et al., 2013).

No entanto desde a semeadura em 09/10/2014 e 08/10/2015 até maturação fisiológica em 26/01/2015 e 01/02/2016, a cultura da soja em 2014/15 não atingiu esse acúmulo real necessário, ficando em torno de 429,6 $\mathrm{mm}$ de água disponível e somente a soja em 2015/16 recebeu um volume de água até maior que o recomendado, em torno de $1.028 \mathrm{~mm}$, o que pode explicar em partes a menor AP em 2014/15.

Com relação aos cultivos de outo-inverno, tanto para o primeiro quanto para o segundo ano agrícola, não houve diferença significativa para $\mathrm{AP}$, que variou de 27,4 a $37,0 \mathrm{~cm}$ em $2014 / 15$ e 91,2 a 95,5 cm em 2015/16 (Tabela 2).

Tabela 2. Altura de Plantas (AP) de soja em sucessão aos cultivos de outono-inverno, durante os anos agrícolas 2014/15 e 2015/16, em Dourados-MS.

\begin{tabular}{ccccc}
\hline \multicolumn{5}{c}{ Altura de Plantas $(\mathrm{cm})$} \\
\hline Anos & Feijão-caupi & Milho safrinha & B. ruziziensis & Consórcio milho-B. ruziziensis \\
\hline $2014 / 15$ & $36,7 \mathrm{bA}$ & $37,0 \mathrm{bA}$ & $30,9 \mathrm{bA}$ & $27,4 \mathrm{bA}$ \\
$2015 / 16$ & $91,2 \mathrm{aA}$ & $95,5 \mathrm{aA}$ & $93,2 \mathrm{aA}$ & $94,2 \mathrm{aA}$ \\
Média & 63,3 & & & \\
\hline C.V.\% & 6,00 & & & \\
\hline
\end{tabular}

Médias seguidas de mesma letra minúscula na coluna e maiúsculas na linha, em cada variável, não diferem pelo teste de Tukey a $5 \%$ de probabilidade.

A análise de variância indicou efeito isolado de anos e cultivares para massa de cem grãos e produtividade. Houve efeito de cultivos somente para massa de cem grãos.

Verificou-se interação entre anos $\mathrm{x}$ cultivos para massa de cem grãos e produtividade; interação entre anos x cultivares somente para massa de cem grãos e cultivos $\mathrm{x}$ cultivares para número de grãos por planta. Verificou-se interação tripla entre anos x cultivos $\mathrm{x}$ cultivares somente para massa de cem grãos (Tabela 3 ).
Houve diferença no NG planta ${ }^{-1}$ entre as cultivares de soja, onde a transgênica BRS 360 RR apresentou superioridade quando comparado a convencional BRS 284, esses resultados podem estar relacionados com a uniformidade espacial entre plantas de uma cultivar, que podem influenciar os componentes de produtividade (Tourino et al., 2002). Segundo Endres (1996) mesmo que as plantas estejam distribuídas uniformemente na área, ainda pode ocorrer competições intraespecíficas. 


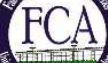

\section{Revista Agrarian}

ISSN: 1984-2538

Tabela 3. Resumo da análise de variância das variáveis número de grãos por planta ( $\left.\mathrm{NG}_{\text {planta }}{ }^{-1}\right)$, massa de cem grãos (M 100) e produtividade de grãos, em anos, cultivos e cultivares de soja em Dourados-MS.

\begin{tabular}{|c|c|c|c|c|}
\hline \multirow[b]{2}{*}{ Fator de variação } & \multirow[b]{2}{*}{ GL } & \multicolumn{3}{|c|}{ 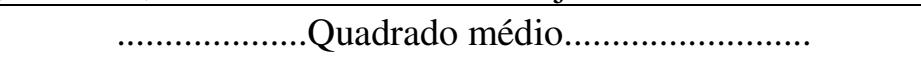 } \\
\hline & & NG planta ${ }^{-1}$ & M 100 & Produtividade \\
\hline Bloco & 3 & 728,856 & 2,149 & 135355,771 \\
\hline Anos & 1 & $0,269^{\text {ns }}$ & $668,545^{*}$ & $96448063,536^{*}$ \\
\hline Erro (a) & 3 & 511,322 & 1,253 & 111143,990 \\
\hline Cultivos & 3 & $817,839^{\text {ns }}$ & $3,889^{*}$ & $165994,813^{\text {ns }}$ \\
\hline Anos x Cultivos & 3 & $703,275^{\mathrm{ns}}$ & $5,628^{*}$ & $613106,966^{*}$ \\
\hline Erro (b) & 18 & 664,572 & 0,725 & 116625,797 \\
\hline Cultivares & 1 & $34,883^{\mathrm{ns}}$ & $15,161^{*}$ & $5023571,375^{*}$ \\
\hline Anos x Cultivares & 1 & $1535,758^{\mathrm{ns}}$ & $53,198^{*}$ & $6426,828^{\mathrm{ns}}$ \\
\hline Cultivos x Cultivares & 3 & $2186,821^{*}$ & $5,586^{\mathrm{ns}}$ & $230318,077^{\mathrm{ns}}$ \\
\hline Anos x Cultivos x Cultivares & 3 & $198,465^{\mathrm{ns}}$ & $8,130^{*}$ & $217427,005^{\mathrm{ns}}$ \\
\hline Erro (c) & 24 & 185,125 & 1,238 & 190720,755 \\
\hline Total & 63 & 40725,861 & 858,319 & 110919997,469 \\
\hline Média & & 140,20 & 10,93 & $2.938,08$ \\
\hline C.V.\% & & 9,70 & 10,17 & 14,86 \\
\hline
\end{tabular}

$\overline{\mathrm{GL}}=$ graus de liberdade, ${ }^{*}$ Significativo $\mathrm{e}^{\mathrm{ns}}$ não significativo $(\mathrm{p}>0,05)$.

Com relação aos cultivo de outono-inverno a BRS 284 apresentou maior NG planta ${ }^{-1}(163,6)$ quando cultivada sobre coberturas de feijão-caupi e consórcio de milho com B. ruziziensis. Por pertencer a família Fabaceae, o feijão-caupi contribui com introdução de até $68 \mathrm{~kg} \mathrm{ha}^{-1}$ de $\mathrm{N}$ no solo através da fixação biológica de nitrogênio
(Castro et al., 2004), em contra partida o consórcio de milho com B. ruziziensis possibilita maior estabilidade produtiva das culturas em sucessão, pela ciclagem de nutrientes e conservação do solo, devido à alta porcentagem de resíduos vegetais sobre o solo (Costa et al., 2012) (Tabela 4).

Tabela 4. Número de grãos por planta $\left(\mathrm{NG}_{\text {planta }}{ }^{-1}\right.$ ) das cultivares de soja, BRS 284 e BRS 360 RR, em sucessão aos cultivos de outono-inverno em Dourados-MS.

\begin{tabular}{ccccc}
\hline \multicolumn{5}{c}{ NG planta $^{-1}$} \\
\hline Cultivares & Feijão-caupi & Milho safrinha & B. ruziziensis & Consórcio milho-B. ruziziensis \\
\hline BRS 284 & $163,6 \mathrm{aA}$ & $130,2 \mathrm{aB}$ & $121,9 \mathrm{bB}$ & $147,9 \mathrm{aAB}$ \\
BRS 360 RR & $136,3 \mathrm{bA}$ & $141,4 \mathrm{aA}$ & $146,1 \mathrm{aA}$ & $133,9 \mathrm{aA}$ \\
Média & 140,2 & & & \\
\hline C.V.\% & 9,17 & & &
\end{tabular}

Médias seguidas de mesma letra minúscula na coluna e maiúsculas na linha, em cada variável, não diferem pelo teste de Tukey a $5 \%$ de probabilidade.

A M 100 foi maior em 2015/16 entre 13,0 a 14,8 g em relação ao ano agrícola 2014/15, entre 6,9 a $8,4 \mathrm{~g}$, possivelmente influenciada pelos menores índices de chuvas desse ano. Para Taiz \& Zeiger (2006) além da perda de turgor das células, o estresse por falta de água faz com que as raízes enviem sinais químicos promovendo o aumento da concentração de ácido abscísico nas folhas, podendo causar queda precoce e diminuição na área foliar da planta.

Com relação aos cultivos de outonoinverno, em 2014/15 a soja apresentou maior M 100, quando cultivada em sucessão ao milho safrinha. O milho safrinha é uma espécie

Ribeiro et al., v.11, n.40, p. 120-131, Dourados, 2018 


\section{Revista Agrarian}

ISSN: 1984-2538

importante para a proteção do solo, pela durabilidade de sua palha, e quando usado em sistema de rotação de culturas pode ser considerado um sistema conservacionista, podendo até favorecer a produtividade da soja pelo acúmulo de nutrientes (Broch \& Ceccon, 2008). Pavão \& Ferreira Filho (2011), explicam que o milho safrinha oferece esses benefícios, além da grande importância econômica que representa, mas enfatizam que quando usado em esquema de rotação de culturas.

Em 2015/16 a soja apresentou maior M 100 quando em sucessão ao milho safrinha e $B$. ruziziensis. O milho safrinha pode ser benéfico para o sistema de plantio direto, quando usado em esquema de rotação de culturas, enquanto que a $B$. ruziziensis cultivada solteira, é uma opção para formação de palha em plantio direto, devido a elevada produção de massa (Nunes et al., 2006), além da capacidade em manter a umidade na superfície do solo. Segundo Carneiro et al. (2014) a cobertura vegetal é responsável pela manutenção da umidade, pois a presença de água afeta o fluxo de calor no solo, que consequentemente controla a evaporação (Tabela 5).

Tabela 5. Massa de cem grãos (M 100) de soja em sucessão aos cultivos de outono-inverno nos anos agrícolas 2014/15 e 2015/16, em Dourados-MS.

\begin{tabular}{ccccc}
\hline \multicolumn{5}{c}{ Massa de cem grãos $(\mathrm{g})$} \\
\hline Anos & Feijão-caupi & Milho safrinha & B. ruziziensis & Consórcio milho-B. ruziziensis \\
\hline $2014 / 15$ & $8,2 \mathrm{bAB}$ & $8,4 \mathrm{bA}$ & $7,1 \mathrm{bAB}$ & $6,9 \mathrm{bB}$ \\
$2015 / 16$ & $13,0 \mathrm{aB}$ & $14,8 \mathrm{aA}$ & $14,6 \mathrm{aA}$ & $14,0 \mathrm{aAB}$ \\
Média & 10,9 & & & \\
\hline C.V.\% & 10,17 & &
\end{tabular}

Médias seguidas de mesma letra minúscula na coluna e maiúsculas na linha, em cada variável, não diferem pelo teste de Tukey a $5 \%$ de probabilidade.

A distribuição normal de pluviosidade no ano agrícola 2015/16 proporcionou melhor M100 das cultivares BRS 284 e a BRS 360 RR, desta forma, as coberturas vegetais dos cultivos de outono-inverno podem ter evitado a perda de água e ocasionado menores variações de temperatura na superfície do solo, favorecendo a produtividade da soja durante esse ano.

No entanto, a BRS 360 RR demonstrou maior M100 no ano agrícola 2014/15 em relação a cultivar BRS 284. Fernandez \& McBride (2002) também observaram que cultivares de soja geneticamente modificadas possuíram superioridade em produção à das cultivares convencionais. Segundo Carmo et al. (2007) cultivares geneticamente modificadas possuem um maior potencial produtivo, devido aos programas de melhoramento, que por meio de seleção buscam cultivares por uma elevada estabilidade produtiva (Tabela 6).

Tabela 6. Massa de cem grãos das cultivares de soja BRS 284 e BRS 360 RR, cultivadas nos anos agrícolas 2014/15 e 2015/16, em Dourados-MS.

\begin{tabular}{ccc}
\hline \multicolumn{3}{c}{ Massa de cem grãos $(\mathrm{g})$} \\
\hline Cultivares & $2014 / 15$ & $2015 / 16$ \\
\hline BRS 284 & $6,3 \mathrm{bB}$ & $14,5 \mathrm{aA}$ \\
BRS 360 RR & $9,1 \mathrm{aB}$ & $13,7 \mathrm{aA}$ \\
Média & 10,9 & \\
\hline C.V.\% & 10,17 & \\
\hline
\end{tabular}

Médias seguidas de mesma letra minúscula na coluna e maiúsculas na linha, em cada variável, não diferem pelo teste de Tukey a $5 \%$ de probabilidade. 


\section{(a) \\ Revista Agrarian \\ ISSN: 1984-2538}

Para a produtividade verificou-se diferença significativa para as duas cultivares avaliadas, a cultivar BRS 284 apresentou menor produtividade com $2.657 \mathrm{~kg} \mathrm{ha}^{-1}$, em relação a BRS $360 \mathrm{RR}$ com $3.218 \mathrm{~kg} \mathrm{ha}^{-1}$.

As médias de produtividade das cultivares de soja mostram que a BRS 360 RR apresentou melhor resultado, devido uma maior adaptabilidade as condições edafoclimáticas da região de Dourados (MS), como por exemplo a maior sensibilidade ao fotoperíodo local. Para Kantolic (2008) a duração das fases e do ciclo de desenvolvimento da soja varia entre genótipos, mas é regulada pela sensibilidade ao fotoperíodo da região (Tabela 7).

Tabela 7. Produtividade das cultivares de soja BRS 284 e BRS 360 RR, cultivadas nos anos agrícolas 2014/15 e 2015/16, em Dourados-MS.

\begin{tabular}{cc}
\hline Cultivares & Produtividade $\left(\mathrm{kg} \mathrm{ha}^{-1}\right)$ \\
\hline BRS 284 & $2.657 \mathrm{~b}$ \\
BRS 360 RR & $3.218 \mathrm{a}$ \\
Média & 2.938 \\
\hline C.V.\% & 14,86
\end{tabular}

Médias seguidas de mesma letra na coluna não diferem pelo teste de Tukey a 5\% de probabilidade.

Para produtividade verificou-se diferença significativa entre os anos agrícolas, onde com produtividade superior em 2015/16, atribuído as melhores condições de precipitação em 2015, e principalmente pela falta de chuva em 2014 durante todo o ciclo da soja resultando em menor produtividade em 2014/15.

Cultivares de soja hoje disponíveis no mercado, exigem relativamente maior quantidade de água durante todo o ciclo, principalmente no estádio reprodutivo, devido ao seu maior potencial genético de produtividade (Ferrari et al., 2015). E com o estresse hídrico a cultura diminui seu potencial osmótico dentro da célula, resultando em uma desidratação celular, que consequentemente afeta o desenvolvimento de órgãos da planta como folhas, hastes e até enchimento de grãos (Morando et al., 2014), o que explica em partes a menor produtividade em 2014/15.

Com relação aos cultivos de outonoinverno, em 2014/15 verificou-se maior produtividade quando em sucessão ao milho safrinha e a B. ruziziensis, com 1.882 e $1.880 \mathrm{~kg} \mathrm{ha}^{-}$ ${ }^{1}$, respectivamente. Porém não diferiu-se estatisticamente do feijão-caupi com produção em torno de $1.724 \mathrm{~kg} \mathrm{ha}^{-1}$. Somente a soja em sucessão ao consórcio milho com B. ruziziensis apresentou menor rendimento em $\mathrm{kg} \mathrm{ha}^{-1}$ (Tabela 8).

A explicação para a maior produtividade da soja em sucessão ao milho safrinha e $B$. ruziziensis, está no fato dessas duas espécies terem a capacidade de reciclar consideráveis quantidades de nutrientes e liberá-los de forma a suprir as necessidades nutricionais da soja, como o fósforo, cálcio e magnésio, principalmente quando usados em rotação de culturas (Cruz et al., 2015; Salton et al., 2008).

A menor produtividade da soja em sucessão ao consórcio milho com $B$. ruziziensis em 2014/15 pode estar relacionado com a capacidade dos resíduos vegetais em manter a umidade na superfície do solo que este cultivo possui. Visto que nos estádios vegetativos da soja em 2014/15, houve constante, mas baixos índices de chuvas e, dessa forma a maior cobertura do consórcio milho com B. ruziziensis, conseguiria manter a umidade por maior tempo, mas apenas na superfície do solo, perdendo-a em seguida para a atmosfera sem ser incorporada ao solo. Ao contrário das outras coberturas, onde a evaporação da umidade da superfície do solo ocorreria mais rápido, estimulando o crescimento das raízes em profundidade (BASSOL, 1998). Desta forma a soja com as raízes mais profundas no subsolo toleraram por maior tempo o período de veranico que ocorreu principalmente em 2014 durante todo o ciclo da cultura.

Torres \& Pereira (2014), avaliando diferentes coberturas antecedendo a cultura do milho e soja observaram que espécies com sistemas radiculares pivotantes, quando em período seco penetram em maior profundidade seguindo a 


\section{(a) \\ Revista Agrarian \\ ISSN: 1984-2538}

umidade no solo, aumentando o volume de exploração, e assim amenizam os problemas decorrentes do estresse hídrico.
Em 2015/16, não houve diferença significativa, independentemente do tipo de cultivo de outono-inverno, com variações entre 4.001 a $4.373 \mathrm{~kg} \mathrm{ha}^{-1}$ de produtividade da soja (Tabela 8).

Tabela 8. Produtividade de soja nos anos agrícolas 2014/15 e 2015/16 em sucessão aos cultivos de outonoinverno em Dourados-MS.

\begin{tabular}{ccccc}
\hline \multicolumn{5}{c}{ Produtividade $\left(\mathrm{kg} \mathrm{ha}^{-1}\right)$} \\
\hline Anos & Feijão-caupi & Milho safrinha & B. ruziziensis & Consórcio milho-B. ruziziensis \\
\hline $2014 / 15$ & $1.724 \mathrm{bAB}$ & $1.882 \mathrm{bA}$ & $1.880 \mathrm{bA}$ & $1.354 \mathrm{bB}$ \\
$2015 / 16$ & $4.001 \mathrm{aA}$ & $4.009 \mathrm{aA}$ & $4.277 \mathrm{aA}$ & $4.373 \mathrm{aA}$ \\
Média & 2.938 & & & \\
\hline C.V.\% & 14,86 & & & \\
\hline
\end{tabular}

Médias seguidas de mesma letra minúscula na coluna e maiúsculas na linha, em cada variável, não diferem pelo teste de Tukey a $5 \%$ de probabilidade.

\section{Conclusão}

Em condições de veranico pronuncia-se o efeito dos cultivos antecessores de milho safrinha e B. ruziziensis no desenvolvimento e nos componentes de produtividade da soja.

A cultivar BRS 360 RR apresentou maior produtividade em relação a BRS 284.

\section{Referências}

ARGENTA, G.; SILVA, P. R. F.; SANGOL, L. Arranjo de plantas em milho: análise do estado daarte. Ciência Rural, Santa Maria, v.31, n.6, p.1075-1084, 2001.

ASSIS, E. P. M.; CORDEIRO, M. A. S.; PAULINO, H. B.; CARNEIRO, M. A. C. Efeito da aplicação de nitrogênio na atividade microbiana e na decomposição da palhada de sorgo em solo de cerrado sob plantio direto. Pesquisa Agropecuária Tropical, Goiânia, v. 33, n. 2, p. 107-112, 2003.

BALBINO, L. C.; CORDEIRO, L. A. M.; OLIVEIRA, P.; KLUTHCOUSKI, J.; GALERANI, P. R.; VILELA, L., 2012. Agricultura sustentável por meio da integração lavoura-pecuária-floresta (iLPF). Reino Unido: IPNI-International Plant Nutrition Institute, 2012. 18p. (IPNI-International Plant Nutrition Institute. Informações agronômicas/versão em português, 138).

BÁRBARO, I. M.; TICELLI, M.; SILVA, G. P.; ARAÚJO, S. C.; MIGUEL, F. B.; SILVA, J. A. A.; BÁRBARO JUNIOR, L. S. Avaliação de soja
(Glycine max) cultivar IAC-23 quanto a eficiência na fixação biológica de nitrogênio, em área de reforma de pastagem em Colina-SP. Unimar Ciências, Colina, v.15, n.01, p.63-70, 2006.

BASSOL, L. H., 1998. Crescimento e distribuição de raízes de videira e sua relação com a prática de irrigação. Petrolina: Embrapa semiárido, 1998. 4p. (Embrapa semiárido. Circular Técnica, 76).

BROCH, D. L.; CECCON, G. Produção de milho safrinha com interação lavoura e pecuária. Maringá, 2008. Disponível em: < http://www.infobibos.com/Artigos/2008_2/safrinh a/index.htm>. Acesso em: 10 mar. 2016.

CARMO, S. L. M.; SANTOS, J. B.; HAGIWARA, W. E.; FERREIRA, J. L. Avaliação do 'stay green' em famílias segregantes de feijão (Phaseolus vulgaris L.). Ciência e Agrotecnologia, Lavras, v.31, n.4, p.953-957, 2007.

CARNEIRO, M. A. C.; CORDEIRO, M. A. S.; ASSIS, P. C. R.; MORAES, E. S.; PEREIRA, H. S.; PAULINO, H. B.; SOUZA, E. D. Produção de fitomassa de diferentes espécies de cobertura e suas alterações na atividade microbiana de solo de cerrado. Bragantia, Campinas, v. 67 , n. 2, p. 455 462, 2008.

CARNEIRO, R. G.; MOURA, M. A. L.; SILVA, V. P. R.; SILVA JÚNIOR, R. S.; ANDRADE, A. M. D.; SANTOS, A. B. Variabilidade da 


\section{(a) \\ Revista Agrarian \\ ISSN: 1984-2538}

temperatura do solo em função da liteira em fragmento remanescente da Mata Atlântica. Revista Brasileira Engenharia Agrícola e Ambiental, Campina Grande, v. 1, p. 99-108, 2014.

CARVALHO, I. R.; KORCELSKI, C.; PELISSARI, G.; HANUS, A. D.; ROSA, G. M. Demanda hídrica das culturas de interesse agronômico. Enciclopédia biosfera, Goiânia, v. 9, n.17, p. 969, 2013.

CASTRO, C. M; ALVES, B. J. R.; ALMEIDA, D. L; RIBEIRO, R. L. D. Adubação verde como fonte de nitrogênio para a cultura da berinjela em sistema orgânico. Pesquisa Agropecuária Brasileira, Brasília, v. 39, n. 8, p.779-785, 2004.

CECCON, G.; STAUT, L. A.; KURIHARA, C. H. Cerrado: Manejo de Brachiaria ruziziensis em consórcio com milho safrinha e rendimento de soja em sucessão. Revista Plantio Direto, Passo Fundo, v. 113, p. 4-8, 2009.

CHIODEROLI, C. A.; MELLO, L. M. M.; GRIGOLLI, P. J.; FURLANI, C. E. A.; SILVA, J. O. R.; CESARIN, A. L. Atributos físicos do solo e produtividade de soja em 9 sistema de consórcio milho e braquiária. Revista Brasileira de Engenharia Agrícola e Ambiental, Campina Grande, v. 16, n. 1, p. 37-43, 2012.

CHIODEROLI, C. A.; MELLO, L. M. M.; GRIGOLLI, P. J.; SILVA, J. O. R.; CESARIN, A. L. Consorciação de braquiárias com milho outonal em plantio direto sob pivô central. Engenharia Agrícola. Jaboticabal, v. 30, n. 6, p. 1101-1109, 2010.

COSTA, H. J. U.; JANUSCKIEWICZ, E. R.; OLIVEIRA, D. C.; MELO, E. S.; RUGGIERI, A. C. Massa de forragem e características morfológicas do milho e da Brachiaria brizantha cv. piatã cultivados em sistema de consórcio. Ars Veterinária, Jaboticabal, v. 28, n. 2, p. 134-143, 2012.

CRUZ, J. C.; PEREIRA FILHO, I. A.; ALBUQUERQUE FILHO, M. R. Árvore do conhecimento "milho": AGEITEC: Agência Embrapa de Informação Tecnológica. Brasília,
2015. Disponível em: < https://www.agencia.cnptia.embrapa.br/gestor/mil ho/arvore/CONT000fy779fnk02wx5ok0pvo4k3s9 32q7k.html>. Acesso em: $31 \mathrm{dez} .2015$.

EMBRAPA Agropecuária Oeste - Empresa Brasileira de Pesquisa Agropecuária. Embrapa apresenta cultivares de soja para safra 2013/2014 em MS. Dourados, 2013. Disponível em:

https://www.embrapa.br/web/mobile/noticias?_bu scanoticia_WAR_pcebusca6_1portlet_javax.portl et.action=visualizarNoticia\&_buscanoticia_WAR _pcebusca6_1portlet_titulo=embrapa-apresentacultivares-de-soja-para-safra-20132014-em-ms\&_buscanoticia_WAR_pcebusca6_1portlet_journ alArticleId=1471969\&p_p_state=normal\&p_p_m ode=view\&p_p_id=buscanoticia_WAR_pcebusca 6_1portlet\&p_p_lifecycle $=1>$. Acesso em: 03 nov. 2015.

EMBRAPA AGROPECUÁRIA OESTE. Clima MS: banco de dados. Dourados, [2016]. Disponível em:

http://www.cpao.embrapa.br/clima/?lc=site/banco -dados/base_dados />. Acesso em: 05 mar. 2016.

ENDRES, V. C. Espaçamento, densidade e época de semeadura. In: Soja: recomendações técnicas para Mato Grosso do Sul e Mato Grosso. Dourados: EMBRAPA-CPAO, 1996. p. 82-85. (EMBRAPA-CPAO. Circular técnica, n. 3).

FERNANDEZ, J.; McBRIDE, W. Adoption of bioengineered crops. Washington: USDA, 2002. 67 p. Agricultural Economic Report.

FERRARI, E.; PAZ, A.; SILVA, A. C. Déficit hídrico no metabolismo da soja em semeaduras antecipadas no Mato Grosso. Nativa, Sinop, v. 3, n. 1, p. 67-77, 2015.

FERREIRA, D. F. SISVAR. Sistema para análise de variância. Lavras: UFL/DEX, 2000, CD-ROM.

FIETZ, R. C.; COMUNELLO, E.; FLUMIGNAN D. L.; Deficiência hídrica na região de Dourados, MS. CONGRESSO BRASILEIRO DE ENGENHARIA AGRÍCOLA, 42., 2013, Fortaleza. Anais... Fortaleza: SBEA, 2013. 1 CDROM; CONBEA 2013. 


\section{(0) \\ Revista Agrarian \\ ISSN: 1984-2538}

FREIRE FILHO, F. R.; RIBEIRO, V. Q.; BARRETO, P. D.; SANTOS, A. A. Melhoramento genético. In: FREIRE FILHO, LIMA, J. A. de A.; RIBEIRO, V. Q. Feijão-caupi: avanços tecnológicos. 1. ed. Brasília, DF: Embrapa Informação Tecnológica, 2005. p. 29-92.

GAVA, R.; FRIZZONE, J. A.; SNYDER, R. L.; JOSE, J, V.; FRAGA JUNIOR, E. F.; PERBONI, A. Estresse hídrico em diferentes fases da cultura da soja. Revista Brasileira de Agricultura Irrigada, Fortaleza, v. 9, n. 6, p. 349-359, 2015.

KANTOLIC, A. G. Control ambiental y genético de la fenologia del cultivo de soja: impactos sobre el rendimiento y la adaptación de genótipos. Revista da Facultad de Agronomía UBA, Buenos Aires, v. 28, p. 63-88, 2008.

KLUTHCOUSKI, J.; FANCELLI, A. L.; DOURADO-NETO, D.; RIBEIRO, C. M.; FERRARO, L. A. Manejo do solo e o rendimento de soja, milho, feijão e arroz em plantio direto. Scientia Agricola, Piracicaba, v. 57, p. 97-104, 2000 .

MORANDO, R.; SILVA, A. O.; CARVALHO, L. C.; PINHEIRO, M. P. A. Déficit hídrico: efeito sobre a cultura da soja. Journal of Agronomic Sciences, Umuarama, v. 3, n. especial, p. 114-129, 2014.

MUNDSTOCK, C., THOMAS, A. L. Soja: Fatores que afetam o crescimento e o rendimento de grãos. Porto Alegre: Departamento de Plantas de Lavoura da Universidade Federal do Rio Grande do Sul, Evangraf, 2005. 31p.

NUNES, U. R.; JÚNIOR, V. C. A.; SILVA, E. B.; SANTOS, N. F.; COSTA, H. A. O.; FERREIRA, C. A. Produção de palhada de plantas de cobertura e rendimento do feijão em plantio direto. Pesquisa Agropecuária Brasileira, Brasília, v. 41, n. 6, p. 943-948, 2006.

PAVÃO, A. R.; FERREIRA FILHO, J. B. S. Impactos econômicos da introdução do milho Bt11 no Brasil: uma abordagem de equilíbrio geral interregional. Revista de economia e sociologia rural, Piracicaba, v. 49, n. 1, p. 81-108, 2011.
REIS, G. N.; FURLANI, C. E. A.; SILVA, R. P.; GERLACH, J. R.; CORTEZ, J. W.; GROTTA, D. C. C. Decomposição de culturas de cobertura no sistema plantio direto, manejadas mecânica e quimicamente. Engenharia Agrícola, Jaboticabal, v.27, n.1, p.194-200, 2007.

RIBEIRO, L. M.; SANTOS, A. L. F.; LEITE, E. M.; KROLIKOWSKI, V.; FACHINELLI, R.; CECCON, G. Produtividade de milho safrinha solteiro e consorciado com braquiária em lavouras de Mato Grosso do Sul. In: SEMINÁRIO NACIONAL DE MILHO SAFRINHA, 13., 2015, Maringá. Anais... Maringá, UEM, 2015. p. 1-5.

RICCE, W. S.; ALVES, S. J.; PRETE, C. E. C. Época de dessecação de pastagem de inverno e produtividade de grãos de soja. Pesquisa Agropecuária Brasileira, Brasília, v. 46, n. 10, p. 1220-1225, 2011.

ROTAÇÃO de culturas. In: TECNOLOGIAS de produção de soja - Região Central do Brasil 2014. Londrina: Embrapa Soja, 2013. p. 15-38 (Embrapa SOJA. Sistema de produção, 16).

SALTON, J. C. Opções de safrinha para agregação de renda nos cerrados. In: ENCONTRO REGIONAL DE PLANTIO DIRETO NO CERRADO, PLANTIO DIRETO NA INTEGRAÇÃO LAVOURA-PECUÁRIA, 1999, Uberlândia. Anais... Uberlândia: Universidade Federal de Uberlândia, p.189-200, 1999.

SALTON, J. C.; MACHADO, L. A. Z.; COSTA, A. R.; LIMA, R. R. B. Potencial de reciclagem e disponibilização de nutrientes por plantas forrageiras perenes cultivadas durante a entressafra em Mato Grosso do Sul. In: REUNIÃO BRASILEIRA DE MANEJO E CONSERVAÇÃO DO SOLO E DA ÁGUA, 17., 2008, Rio de Janeiro. Manejo e conservação do solo e da água: Anais... Rio de Janeiro, SBCS, UFRRJ, 2008. 1 CD-ROM.

SANTOS, H. G.; JACOMINE, P. K. T.; ANJOS, L. H. C.; OLIVEIRA, V. A.; LUMBRERAS, J. F.; COELHO, M. R.; ALMEIDA, J. A.; CUNHA, T. J. F.; OLIVEIRA, J. B. Sistema brasileiro de classificação de solos. 3. ed. Rio de Janeiro: Embrapa Solos, 2013. 353 p. 


\section{(-) \\ Revista Agrarian \\ ISSN: 1984-2538}

TAIZ, L.; ZEIGER, E. Fisiologia vegetal. 3.ed. Porto Alegre: Artmed, 2006. 722p.

TORRES, J. L. R.; PEREIRA, M. G. Produção e decomposição de resíduos culturais antecedendo milho e soja num latossolo no Cerrado mineiro. Comunicata scientiae, Bom Jesus, v. 5, n. 4, p. 419-426, 2014.

TOURINO, M. C. C.; REZENDE, P. M.; SALVADOR, N. Espaçamento, densidade e uniformidade de semeadura na produtividade e características agronômicas da soja. Pesquisa Agropecuária Brasileira, Brasília, v. 37, n. 8, p. 1071-1077, 2002. 